\title{
Strategies for Inculcating Life Skills in CBSE Schools of Varanasi City
}

\author{
Poonam Tiwari ${ }^{1^{*}}$ and Anjali Bajpai ${ }^{2}$
}

${ }^{1}$ Post Doctoral Research Fellow(ICSSR), Faculty of Education (K), BHU, Varanasi, Uttar Pradesh, India

${ }^{2}$ Professor, Faculty of Education (K), BHU, Varanasi, Uttar Pradesh, India

*Corresponding author: punnu.tiwari77@gmail.com

Received: $20-09-2020$

Revised: $25-11-2020$

Accepted: $11-12-2020$

\begin{abstract}
Life Skills Education is a value addition programme for children and youth to understand self and enable them to analyze their capacity to enhance the function in most productive way so they empower efficiently in challenging situations. Life Skills include psychosocial competencies and interpersonal skills that help people make informed decisions, solve problems, think critically and creatively, communicate effectively, build healthy relationships, empathize with others, and manage their lives in a healthy and productive manner. Life Skills are needed at all stages and phases of life, but it becomes important for children and adolescents because this is crucial stage on which future of individual depends. The Life Skills programme is a very important and integral part of the educational system worldwide. It is a school based programme where Life Skills are imparted in a supportive learning environment. The Central Board of Secondary Education (CBSE), India has introduced Life Skills Education as an integral part of its curriculum and provides guidelines for transaction of the ten core Life Skills. Though Life skills are often learned indirectly through experience and practice but it would be enhanced directly by implementing through a dedicated Life skills curriculum by using proper and suitable transaction methods. In school based programme to teach Life Skills in supportive leaning environment teacher's role is very crucial. Teachers should be act as positive role models for students as Life Skills are better caught then taught. So it is significant to know what strategies teachers build to inculcate the Life Skills among students. The present paper focuses on the ten core Life Skills necessary for students and the strategies used by CBSE teachers at upper primary level of Varanasi City to transact and internalize these Life Skills among students. Survey method was used for the study. Sample consisted of 225 teachers teaching at upper primary level from 31 CBSE schools selected purposively. Content analysis was used to analyse data obtained from questionnaire prepared by reseacher, frequency and percentage were calculated. The findings provide information regarding strategies practiced by CBSE teachers would be helpful for designing Life Skills Training Module.
\end{abstract}

Keywords: Life Skills, Life Skills Education, Strategies for Life Skills, CBSE

Education with holistic perspective is concerned with the development of every person's intellectual, emotional, social, physical, artistic, creative, and spiritual potentials. Life skills are objectives of holistic education. Life Skills Education is helpful in achieving holistic development. It is all about educating an individual how to balance life in adverse situations. It fosters an environment where the natural abilities of child bloom perfectly; it brings their hidden strengths forward, enabling them to fight for survival and existence.

Life Skills Education program is a very important and integral part of the educational system

How to cite this article: Tiwari, P. and Bajpai, A. (2020). Strategies for Inculcating Life Skills in CBSE Schools of Varanasi City. Educational Quest: An Int. J. Edu. Appl. Soc. Sci., 11(4): 197-204.

Source of Support: None; Conflict of Interest: None $\infty$ 
worldwide. UNICEF and WHO recognizes that life skills are generally applied in various aspects of life such as in the context of health, social events like human relationships, learning about rights and responsibilities etc. The development of Life skills Education is dynamic, lifelong, and an evolving process. Its development depends on a closely -knit partnership between the trinity of the learning process - the child, the teacher, and the parent. Parents lay the foundation of Life skills which is further accelerated and strengthen by the teachers. They make proper strategies to transfer these skills to the students. Life Skills Education is developing social, emotional and thinking skills among students, so a teacher should plan strategies accordingly. In a country like ours, where resources and trained professionals are sparse and few, it is more to be practical to involve and work with the teachers.

\section{What are Life Skills?}

Life skills are inborn abilities that can be grown gradually. These abilities have to be developed in the students by making them aware about their potentialities and leading them towards excellence by practicing.

World Health Organization (1997) defines Life Skills as "the abilities for adaptive and positive behaviour that enable the individuals to deal effectively with the demands and challenges of everyday life". Here 'adaptive' means that a person is flexible in approach and is able to adjust in different circumstances and 'positive behavior' implies that a person is forward looking and even in challenging situations, can find a ray of hope.

United Nations International children's Emergency Fund (UNICEF) defines Life Skills as "a behaviour change or behaviour development approach designed to address a balance of three areas: Knowledge, Attitudes and Skill.

\section{Key Life Skills}

To develop healthy human beings in the world, World Health Organization (WHO) in 1997 has identified ten skills which help the person to develop into healthy responsible and productive citizen.
Life Skills fall into three basic categories which compliment, supplement and reinforce each other: Social skills, Emotional skills, and Thinking skills. All these skills are interrelated and reinforce each other. Together, they are responsible for our psychosocial competence; build our Self-Esteem and self efficacy and nurture holistic development. The ten core Life Skills as are- Self-Awareness, Empathy, Critical Thinking, Creative Thinking, Decision Making, Problem Solving, Effective Communication, Interpersonal Relationships, Coping with Stress and Managing Emotions.

Self-awareness includes recognition of 'self', our character, our strengths and weaknesses, desires and dislikes. Developing self-awareness can help us to recognize when we are stressed or feel under pressure. It is often a prerequisite to effective communication and interpersonal relations, as well as for developing empathy with others. Developing self-awareness is helpful in stressful conditions.

Empathy is the ability to understand and share the feelings of others. Showing Empathy involves seeing things from another person's perspective; it is the capacity to place oneself in another position. To have a successful relationship with our loved ones and society at large, we need to understand and care about other peoples' needs, desires and feelings. Empathy can improve social interactions, especially, in situations of ethnic or cultural diversity. Empathy can also help to encourage nurturing behaviour towards people in need of care and assistance, or tolerance, as is the case with AIDS sufferers, or people with mental disorders.

Critical thinking is the ability to think clearly and rationally about what to do or what to believe. It is an ability to analyze information and experiences in an objective manner. It enhance language and presentation skills, promotes creativity, foundation for scientific approach and also helpful in problem solving and decision making.

Creative thinking is a way of looking a problem with new perspective that suggests unorthodox solutions. It generates new imaginative ideas into reality. It is a novel way of seeing or doing 
things that is characteristic of four components - fluency, flexibility, originality, and elaboration. Being helpful in problem solving and decision making makes life really interesting and worth living.

$\square$ Decision-making helps in the process of making important decision, help us to deal constructively with decisions about our lives. This is helpful in leading effective and meaningful life.

$\square$ Problem solving is the process of finding solutions to complex issues of life. It helps us to deal constructively with problems in our lives. It requires critical and creative thinking. Unresolved issues lead to mental stress which is not good for healthy and balanced personality, so this is important for all individuals.

$\square$ Interpersonal relationship is skills we use to communicate and interact with people. People with these skills are usually more successful in their personal and professional life. This may mean being able to make and keep friendly relationships, which can be of great importance to our mental and social well-being.

$\square$ Effective communication is the foundation of all human relationship. It is exchange of ideas, information, knowledge effectively. It means that we are able to express ourselves, both verbally and non-verbally, in ways that are appropriate to our cultures and situations. This skill is fundamental to success in many aspect of life.

Coping with stress Coping refers to the thoughts and actions we use to deal with a threatening situations. Stress has a major impact on mental and physical health. It means recognizing the sources of stress in our lives, recognizing how this affects us, and acting in ways that help us control our levels of stress, by changing our environment or life-style and learning how to relax.

Coping with emotions Emotions are strong feelings in response to situations, issues and needs. Coping with emotions involves recognizing emotions and how emotions influence our behavior. Being able to respond to emotions are important because intense emotions like anger, sorrow, sadness can have negative effects on our health if we do not react appropriately. Emotions unsuppressed energy should be directed in positive direction to overcome depression and frustrations.

\section{Life Skills Education in School Settings}

Anyone who wants to lead a meaningful life, needs Life Skills and these are applicable to all ages, but it becomes important for children and adolescents because this is crucial stage on which future of individual depends. Since Early adolescence (10-14 years) is the period of recognition of self, ability to think and solve problems hence life skills programme would be more effective at this stage. The Life Skills programme is a school based programme where Life Skills are imparted in a supportive learning environment. Life Skills Education is embraced by educational system worldwide however in Indian scenario it is in blooming stage. Central Board of Secondary Education (CBSE), India has recognized that Life Skills are necessary to develop scholastic as well as co-scholastic areas, and hence, has made Life Skill Education as a compulsory component in its curriculum. Life Skills training in schools must meet the social and emotional developmental needs of students. The schools are advised to adapt an inter-disciplinary approach for transacting Life Skills Education. The transaction should be both through formal modes of learning as well as through co-curricular activities and other informal approaches to learning.

Life Skills Education can be designed to be spread across the curriculum, to be a separate subject or to be in integration. Life Skills Education cannot be facilitated on the basis of information or discussion alone. It is not only an active learning process, but it must also include experimental learning i.e. practical experience, and reinforcement of the skills for each learner in a supportive learning environment.

The strength of positive behavior depends upon the depth of skills acquired by the individual, so some powerful strategies must be adapted to deepen ten core life skills among students. These strategies and activities should internalize among students through practice so that they can utilize their full potential.

Two types of approaches can be used by teachers for empowering Life skills among students. 
1. The Teacher centered Approach-(Expository Approach) where teacher exposes learners to knowledge.

2. The learner centered Approach-(Heuristic Approach) where learners are encouraged to find information on their own through interactive activities.

In school based programme to teach Life Skills in supportive leaning environment teacher's role is greater. Teachers are responsible to develop and to make practice essential Life Skills and strengthen these with the help of effective weapon i.e. Teaching strategies.

\section{Strategies to Enhance Life Skills}

Life skills are not just qualities which are to be imbibed, but these skills are to be practice. Though Life skills are often learned indirectly through experience and practice but it would be enhanced directly by implementing through a dedicated Life skills curriculum and integrated into scholastic and co-scholastic area.

According to studies of Abobo (2012), the findings show that the participatory teaching and learning methods recommended for the teaching of LSE includes: case studies, brainstorming, field visits, pane discussions, storytelling, song, group discussion, debates, posters, role play, games, projects, poetry recitals and drama. According to studies of Adhiambo, L.P. (2013) the use of discussion and case study were the major teaching activities (25\% each)and Role play, games and storytelling were all represented by $16.7 \%$ each, used in teaching Life Skills Education among the teachers in secondary schools of Uriri and Awendo districts.

Nivedita, \& Singh B. (2016) and Prajapati, R., Sharma, B. \& Sharma, D (2017) have mentioned strategies as classroom discussion, brainstorming, roleplays, smallgroup/buzzgroup, educational games and simulations, storytelling, debates, situation analysis and case studies to impart life skills education in classroom setting. Yadav, V. \& Kesharwani, R.M. (2017) in the article 'Imparting Life-Skills Education through Constructivist Approach' described Constructive Approach as more effective and appropriate approach to impart Life Skills Education. They specified some important and major constructivist Methods [Distributed Cognition Method and Co-operative Learning Method-Class discussion, brain storming, storytelling, debate, Situation Analysis \& case study methods, other creative methods (Role Play, games, poetry recitation, dance \& music), Distributive Cognition Method and Co-operative Learning Method]. These strategies are also suggested in the CBSE Teacher's manual for Life Skills Education \& CCE of IX \& X (pg.no.10-15). We are describing some strategies briefly here.

\section{Classroom Discussions}

Discussion involves exchange and sharing of ideas, experiences, facts and opinion on given topics. It is a purposeful conversation proceeding towards a certain objective the conversation can be used in large or small groups. The class examines a topic of interest with the goal of better understanding an issue or skill, reaching the best solution, or developing new ideas and directions for the group. It enables students to deepen their understanding of the topic and personalize their connection to it. Most life skills discussion topics are the seeds for open ended discussion. It helps in developing skills, in listening, assertiveness, and empathy.

\section{Brainstorming}

It is a free expression of ideas among participants on a given issue or question .It allows students to generate ideas quickly and spontaneously often brief period of time. Quantity of ideas is the main objective of brain storming, evaluating or debating the ideas occurs later. It helps students to use their imagination and think out of the box. It is good discussion starter because the class can creatively generate ideas. It is essential to evaluate the pros and cons of each idea or rank ideas according to certain criteria. It is helpful in developing specific skills as critical thinking, creative thinking, communication skills.

\section{Role Plays}

Role plays is an informal dramatization, short drama episodes in which participant experience how a person feels in a similar real life situation. It is helpful in developing specific skills such as negotiation, assertiveness, communication and selfawareness practicing skills; increasing empathy for others increasing insight into own feelings. 


\section{Small Group/Buzz Group}

Large class is divided into smaller groups of six or less and given a short time to accomplish a task, carry out an action, or discuss a specific topic or problem. Groups are helpful when the time is limited as it maximizes student input. It allows students interactions, to know one another better increases the likelihood that they will consider how another person thinks. It helps students hear and learn from their peers also enhances team building and team work. It is helpful in developing specific skills such as empathy, interpersonal relationship, communication skill and decision making.

\section{Educational Games and Simulations}

Simulations are activities structured to feel like the real experience. Students also play games as activities. Games promote active learning, decision making, discussion and fun. It promotes healthy competition among participants as they work hard to prove their talents. It enables students to use their knowledge, attitude and skills. It can help in developing skills as critical thinking, problem solving and decision making.

\section{Story-Telling}

The instructor or students tell a story to a group. Pictures, comics and photo novels, filmstrips and slides can supplement. Students are encouraged to think about and discuss important points or methods raised by the story after it is told. It can help develop critical thinking skills, creative skills to write stories, or interact to tell stories, attention, concentration, listening skills and develops patience and endurance. Stories can be composed or collected based on specific themes on Life Skills.

\section{Debates}

A debate is a discussion which involves two opposing parties with each group expressing opinions or views about a given subject. Each group competitively attempts to win the other to their side of the argument. It provides opportunity to address a particular issue in depth and creatively debates can be used to teach life skills like higher thinking skills, Negotiation Effective communication Assertiveness Decision-making.

\section{Situation Analysis}

Situation analysis activities allow students to think about, analyze and discuss situations they might encounter. It gives a chance to analyze, explore, challenges, dilemmas and safely test solutions for providing opportunities for working together in groups, sharing idea, new learning and gives insight and promotes sometimes to see things differently. During situation analysis, students are allowed to explore problems and safely test solutions. It provides opportunities to work hard, share feelings and develop critical thinking.

\section{Case Studies}

Case studies are real life stories that describe in detail what happened to a community, family school, or individual. This is like powerful catalysts for thought and discussion. Engaging in this thinking process, students improve their own critical thinking, decision-making skills. It also gives chance to confront with risks or any challenges and find ways to cope with it.

Beside above mentioned strategies there are some more strategies to impart life skills education.

\section{Miming}

Miming is acting without words by use of gestures, signs, physical movement and facial expression. Miming is suitable for communicating sensitive messages. It helps in expressing messages which cannot easily be put into words. It is to enhance acquisition of various life skills like Interpersonal relationships empathy, coping with stress and coping with emotions.

\section{Poetry and Recitals}

These are compositions which capture events, themes and situations in a precise manner. They can be in form of songs, recitations, chants or they can be dramatized they communicate feelings, opinions, ideas, habit and other experiences. Skills encompassing the development of speech, self expression stage confidence and expression of feelings.

\section{Question and Answer Method}

It is the method where learners find out information through asking questions and getting answers. 
Questioning enables the teacher to create a link between familiar and unknown concepts arouse motivation and curiosity among learners. It is an effective method of teaching Life Skill Education because it stimulates learner thinking and creativity.

\section{Songs and Dances}

Songs are musical compositions on contemporary issues and themes and convey positive messages in the society. They can be used in character building where positive characteristics/values are reinforced life skills as example self awareness, communication skills and conflict resolution can be strengthen through it. It is linked to stress reduction. Dancing involves co-ordination of body movements which generate joy and cheer among the participants. It develops self confidence of children. Song, music and dance can help children become more imaginative, self-aware and collaborative global citizen.

These strategies can be enhanced and internalized through regular practice of various kinds of activities involve in it to fix life skills among students, as they are the important building blocks for being a dynamic citizen, who can cope up with future challenges, and survive well.

\section{The Present Study}

The present study 'Strategies for inculcating Life Skills in CBSE Schools of Varanasi City' was aimed for identifying the strategies used by teachers to transact Life Skills at upper primary level in CBSE school of Varanasi City.

Methodology: The present study was a survey where the purpose was to study the strategies used by CBSE teachers in classroom settings.

Sample: In the present study 31 schools were selected through purposive sampling technique. Sample consisted of 225 teachers teaching at upper primary level CBSE schools of Varanasi city.

Tool: A Questionnaire was prepared for collecting information regarding strategies used by teachers to transact Life Skills at upper primary level in CBSE school of Varanasi City.

Techniques of Data Analysis and Statistics used: Content analysis was used to form categories of data obtained from open ended questionnaire. Frequency and percentage were calculated.

\section{RESULTS AND DISCUSSION}

All the teachers (100\%) mentioned that they incorporate Life Skills during classroom teaching. (56.42\% teachers stated that they do this during teaching by relating content with life skills, $14.28 \%$ teachers shared experiences and giving daily life examples, $12.85 \%$ teachers recommended for different teaching strategies for this, $2.14 \%$ teachers focused on practical activities to explore Life Skills, 2.14\% teachers focused on area to enhance social skills, two teachers stated that increasing awareness about it, two teachers proposed that they design new activities as per need, $8.57 \%$ teachers suggested some other views).

On most preferred teaching method used to transact Life Skills at upper primary level in CBSE school of Varanasi City, following data were obtained:

\begin{tabular}{llll}
\hline Sl. No. & Teaching Method & Frequency & Percentage \\
\hline 1 & Discussion & 26 & 18.57 \\
2 & Story Telling & 22 & 15.71 \\
3 & Educational Games & 15 & 10.71 \\
4 & Debate & 15 & 10.71 \\
5 & Question \& answer & 14 & 10.00 \\
6 & Brain storming & 13 & 09.28 \\
7 & Role play & 09 & 06.42 \\
8 & Small group and buzz & 09 & 06.42 \\
& group & & \\
9 & Song and dances & 08 & 05.71 \\
10 & Poetry \& recitals & 05 & 03.57 \\
11 & Miming & 04 & 02.85 \\
12 & Case study & - & - \\
13 & Situation analysis & - & - \\
& method & & $\mathbf{9 9 . 9 5}$ \\
\hline
\end{tabular}

Note: (85 Unfilled and half filled questionnaire were not taken for analysis).

Though above data focused on most preferred teaching method used by teachers, but majority of the teachers $(94.56 \%)$ specified that they use different teaching methods in combination. Most of the teachers (84\%) generally preferred - Discussion, Story Telling, Educational Games, Debate, Question \& Answer methods, Brain storming, Role play; Other methods (Small group and buzz group, Song and dances, Poetry \& recitals, Miming) were also used by 
them depending on situation; Case study and Situation analysis method were also used as per need and requirement, but were not preferred as first choice.

\section{CONCLUSION}

On the basis of above findings it may be concluded that teachers transact Life Skills by incorporating activities during classroom teaching. They design new, interesting, innovative activities for imparting Life Skills to students. They plan strategies to perform Life Skills activities by following participative, collaborative, and experiential and child centric methodology.

Mostly teachers stated that during class teaching they relate content with Life Skills, some teachers had view that shared experiences and giving daily life examples, some other recommended for different teaching strategies for transaction of life skills. Discussion is most preferred teaching method followed by Story Telling, Educational Games, Debate, Question \& Answer methods, Brain storming, Role play, Small group and buzz group, Song and dances, Poetry \& recitals, Miming is least preferred method used to transact Life Skills. Multiple teaching strategies are applied in classroom. Thus, it is clearly indicated that all the teaching methods are almost utilized in transacting Life Skills among students at upper primary level in CBSE school of Varanasi City.

It is advisable that teachers should make proper strategies to explore and internalize Life Skills among students. Though they get adequate support from schools, but it is not sufficient, so Government should come forward to support schools so that teachers could be efficient to sharpen the student's future by equipping them with Life Skills and they can cope up with future challenges, become strong and survives well in changing society.

\section{REFERENCES}

Abobo, F. 2012. Thesis: Challenges facing implementation of life skills education in secondary schools in Trans-nzoia West District, Kenya. Kenyatta University: Nairobi.

Adhiambo, L.P. 2013. Implementation of Life Skills Education in Uriri EAwendo Districts Migori County, Research Project Kenya.

Behrani, P. 2016. Implementation aspects of Life Skills Education Program in CBSE Schools. Research Paper Psychology, 2(3): 68-71.
Bwayo, J.K.W. 2014. Primary School Pupils Life Skills. Development: Case for Primary School Pupils Development in Uganda (Ph.D. Thesis). M.I. College Limerick.

Central Board of Secondary Education. 2013. Life Skills CBSE Teacher's Manual for class $6^{\text {th }}$. Retrieved on Aug, 25, 2016 http://cbseacademic.in/web_material/Lifeskills/1_Life\%20 Skills\%20Class\%20VI.pdf

Central Board of Secondary Education. 2013. Life Skills CBSE Teacher's Manual for class $6^{\text {th }}$. Retrieved on Aug, 25, 2016 http://cbseacademic.in/web_material/Lifeskills/2_Life\%20 Skills\%20Class20VII.pdf

Central Board of Secondary Education. 2013. Life Skills CBSE Teacher's Manual for class 8 ${ }^{\text {th }}$. Retrieved on Aug, 25, 2016. http://cbseacademic.in/web_material/Lifeskills/2_Life $\% 20$ Skills\%20Class20VII.pdf ass $\% 2$

Githaiga, S.N., Wanjiru, G.L. and Thinguri, R. 2014. An Exploration of Teachers' Attitude towards Life Skill Education: A Case Study of Secondary schools in Thika West District, Kiambu County. Journal of Education and Practice, 5(34): 133-141.

Global Evaluation of Life Skills Programmes, UNICEF, 2012. Evaluation Report http:// www.Unicef.Org/Evaluation/ Files/USA-2012-011-1_GLSEE.Pdf Indicative questions adapted from UNICEF, Global Evaluation of Life Skills Education Programmes

James, O. 2010. Awareness and Application of Life Skills Education in Primary Schools in Post-Conflict Areas: A Case of Kalaki County Kaberamaido District. Unpublished M.Ed Dissertation, Makerere University.

Khera, S. and Khosla, S. 2012. A Study of core life Skills of adolescent in relation to their Self concept Developed through Yuva School Life Skill Programme. International Journal of Social Science E Interdisciplinary Research, 1(11): 115-125.

Life Skills Education for Children and Adolescents in Schools, Introduction and Guidelines to Facilitate the Development and Implementation of Life Skills Programmes, 1997. Programme of Mental Health, Geneva, WHO, http://www. Asksource.Info/Pdf/31181_Lifeskillsed_1994.Pdf

Life Skills in Non-Formal Education: A Review, UNESCO, New Delhi and Indian National Commission for Cooperation wit UNESCO, 2001. Http//Www.Ibe. Unesco.Org/Fileadmin/User_Upload/HIV_And_AIDS/ / Life_Skills_In_Non-Formal_Education.Pdf.

Life Skills -CBSE Retrieved on Aug, 2017 www.cbse.nic.in/ cce/life_skills_cce.pdf

Mugambi, M.M. and Muthui, R.K. 2013. Influence of structural context on Implementation of Secondary School Life Skills Curriculum in Kajiado County, Kenya. International Journal of Education and Research, 1(22): 1-25.

Munsi, K. and Guha, D. 2014. Status of Life Skills Education in Teacher curriculum of SAARC Countries: A Comparative Evaluation. Journal of Education \& Social Policy, 1(1): 93-99.

National Council of Educational research and Training, NCF. 2005. A Document of NCERT. National Curriculum 
Framework-2005. Retrieved from http://www.ncert.nic. in/rightside/links/pdf/framework/english/nf2005.pdf on March 2016.

Nivedita, and Singh, B. 2016. Life Skills Education: Needs and Strategies. Scholarly Research Journal for Humanity Science English Language, 3(16): 3800-3806.

Parvathy, V. and Pillai, R.R. 2015. Impact of Life Skills Education on Adolescents in Rural School. International Journal of Advanced Research, 3(2): 788-794.

Prajapati, R., Sharma, B. and Sharma, D. 2017. Significance of Life Skills Education. Contemporary issues in Education Research. First Quarter 2017, vol. 10, Nov. 1, 1-5.

Singh, D. and Sharma, P. 2016. Status of Life Skill Education and Its Practices in India. IJEAR, 6(1): 67-69.

Tripathy, A. 2016. A Beautiful Life: Life Skills Education. New Delhi: Global Publication.
Venkatesh, Y.B. 2009. A Study of the effectiveness of Life Skills Education on Attitude, Self-concept and Problem Solving Ability in Mathematics. Department of Post Graduate Studies and Research in Education, Jnana, Sahydri, KUVEMPU University, Karnatka, India.

Wairimu, K.H. 2015. Factors Influencing Implementation of Life Skills Education in primary schools in Starehe sub-county, Nairobi county, Kenya. Unpublished M.Ed Dissertation, Nairobi University.

WHO, 1997. Meaning of Life Skills. Retrieved on September, 2016, from www.who.org/ls.

Yadav, V. and Kesharwani, R.M. 2017. Imparting Life-Skills Education through Constructivist Approach. University News, 55(20): 7-10. 